\section{Pharmacokinetic and Pharmacodynamic Modifiers of EF5 Uptake and Binding}

TO THE EDITOR: Chitneni et al. compared ${ }^{18} \mathrm{~F}$-labeled and unlabeled 2-(2-nitro-1H-imidazol-1-yl)- $N$-(2,2,3,3,3-pentafluoropropyl)acetamide (EF5) uptake in 1 rat and 2 murine xenograft tumor models (1). For the H460 model (rat), concern was expressed over retention of label, determined by autoradiography, in areas not positive for EF5 adducts as determined by immunohistochemistry (1). There are 3 sources of signal for the autoradiographs (and PET images): parent drug, metabolized unbound drug, and metabolized bound drug. About $25 \%$ of bioreductively metabolized EF5 is bound to macromolecules (2). Thus, PET image or autoradiograph contrast is affected by pharmacokinetic loss of parent and metabolized unbound drug. The half-life of EF is $150 \mathrm{~min}$ in rats but only $50 \mathrm{~min}$ in mice (3). Thus, at the 3-h time point assessed, 5 times more free and metabolized unbound drug is expected in the rat H460 than in murine tumors. To optimally compare immunohistochemistry with autoradiography, one should fix both sections; fixation removes the free drug and metabolized unbound products. For typical hypoxic tumors in rats, about $75 \%$ of the total radioactivity disappears for the fixed sections. What remains is a near-perfect representation of the immunohistochemically determined bound EF5 (4). In humans, the half-life of EF5 and similar drugs is longer than that in rats (much greater than the ${ }^{18} \mathrm{~F}$ isotope half-life), resulting in a fundamental decrease in PET contrast compared with mice. If the observed effect was caused by oxygen-independent EF5 metabolism, as hinted by the authors, this would be the first example of such metabolism found for EF5.

For the same H460 model, higher contrast at a 10-fold reduced drug concentration was explained by a possible decrease in drug half-life (1). In humans there is only a 2-fold decrease in the half-life of EF5 for a concentration decrease of about 10,000. An alternative explanation lies in the kinetics of drug binding as a function of drug and oxygen concentration. For many 2-nitroimidazoles, binding will change from first order to approximately half order in drug concentration at severely low oxygen concentrations $(4,5)$. The result is an increase in relative binding to severely hypoxic cells as drug concentration decreases. Thus, if the H460 tumors contained regions of severe hypoxia, they would show the concentration effect observed.

In the Chitneni paper, the authors suggest that uptake of 2nitroimidazoles such as EF5 selects for tissues that have a partial pressure of oxygen less than $10 \mathrm{~mm} \mathrm{Hg}$. In our experience, EF5 binding will change continuously with tissue partial pressure of $\mathrm{O}_{2}$ and is severalfold higher at $10 \mathrm{~mm} \mathrm{Hg}$ than at more physiologic oxygen levels (6). This finding has relevance to additional comparisons between immunohistochemistry and PET or autoradiography for the tumors described: a relatively large volume of moderate hypoxia will look the same on a PET image as distributed smaller volumes of more severe hypoxia. This may be true for all imaging agents but has been studied in detail only for EF5. The immunohistochemistry image of the PC3 tumor (Fig. 2 of Chitneni et al.) is illustrative.

COPYRIGHT (c) 2015 by the Society of Nuclear Medicine and Molecular Imaging, Inc.
In this tumor, contiguous regions of "hypoxia" extend over many square millimeters of tissue. We have described this observation as macroscopic regional hypoxia (7). Although a small area of decreased binding is seen around a large artery pair or vein pair, there are undoubtedly many hundreds of individual vessels in the total tumor cross section shown. This important observation appears to be the first example published of macroscopic regional hypoxia in an epithelial murine tumor. In contrast, the HCT116 tumor (Fig. 3 of Chitneni et al.) shows a highly repetitive pattern of high and low EF5 binding, with the low values undoubtedly centered on oxygen-carrying vessels, consistent with classic diffusion-limited hypoxia (4). Clearly, "hypoxia" is different in these 2 tumor types.

In summary, we suggest some additional interpretations of the very nice data presented by the Duke group.

\section{REFERENCES}

1. Chitneni SK, Bida GT, Zalutsky MR, et al. Comparison of the hypoxia PET tracer ${ }^{18} \mathrm{~F}-\mathrm{EF} 5$ to immunohistochemical marker EF5 in 3 different human tumor xenograft models. J Nucl Med. 2014;55:1192-1197.

2. Raleigh JA, Koch CJ. The importance of thiols in the reductive binding of 2-nitroimidazoles to macromolecules. Biochem Pharmacol. 1990;40:2457-2464.

3. Koch CJ, Lord EM, inventors; Trustees of University of Pennsylvania, University of Rochester, assignee. Detection of hypoxic cells by monoclonal antibody recognizing 2-nitroimidazole adducts. U.S. patent 5540908. July 30, 1996.

4. Koch CJ, Evans SM. Optimizing hypoxia detection and treatment strategies. Semin $\mathrm{Nucl} \mathrm{Med}$. In press.

5. Koch CJ. The reductive activation of nitroimidazoles; modification by oxygen and other redox-active molecules in cellular systems. In: Adams GE, Breccia A, Fielden EM, Wardman P, eds. Selective Activation of Drugs by Redox Processes. New York, NY: Plenum Press; 1990:237-247.

6. Koch CJ, Evans SM, Lord EM. Oxygen dependence of cellular uptake of EF5 [2(2-nitro-1H-imidazol-1-yl)-N-(2,2,3,3,3-pentafluoropropyl)acetamide]: analysis of drug adducts by fluorescent antibodies vs bound radioactivity. Br J Cancer. 1995; 72:869-874.

7. Koch CJ, Jenkins WT, Jenkins KW, et al. Mechanisms of blood flow and hypoxia production in rat 9L-epigastric tumors. Tumor Microenviron Ther. 2013;1:1-13.

Cameron J. Koch
Sydney M. Evans
University of Pennsylvania Medical Center
195 John Morgan Building
Philadelphia, PA 19104
E-mail: kochc@mail.med.upenn.edu

Published online Mar. 5, 2015.

DOI: 10.2967/jnumed.114.151662

REPLY: We thank Drs. Koch and Evans for their insightful comments on our recent article on the hypoxia imaging agent ${ }^{18}$ F-EF5 (2-(2-nitro- $1 H$-imidazol-1-yl)- $N$-(2,2,3,3,3-pentafluoropropyl)-acetamide) (1). In their letter, Koch and Evans have suggested possible reasons for the significant retention of unbound ${ }^{18} \mathrm{~F}-\mathrm{EF} 5$ in $\mathrm{H} 460$ tumor xenografts in rats compared with that in tumors grown in mice as described in our article. We agree that the differences in drug half-life between rats and mice could be the major factor contributing to higher retention of unbound ${ }^{18} \mathrm{~F}-\mathrm{EF} 5$ in rat tumors, especially when the radiotracer is coadministered with its nonradioactive analog for immunohistochemical 
analysis of bound EF5 adducts on tumor sections. We used $2.5 \mathrm{~h}$ for single-time-point imaging ( $3 \mathrm{~h}$ after injection for tumor collection and autoradiography) to enable direct comparison among the tumor models, and based on the literature reports suggesting that 2$3 \mathrm{~h}$ is generally an optimal time window for imaging after ${ }^{18} \mathrm{~F}-\mathrm{EF} 5$ injection (2-4). For comparison of autoradiography and immunohistochemical images of ${ }^{18} \mathrm{~F}-\mathrm{EF} 5 / \mathrm{EF} 5$ binding in tumors, we agree that fixation of tumor sections may remove unbound ${ }^{18} \mathrm{~F}$ activity and yield autoradiography images that may closely match the EF5-immunohistochemical images. In our studies, we used a standard method of comparing images derived from whole tumor sections (untreated) with the hypoxia profile determined from EF5-bound adducts in immunohistochemical images because the purpose of this analysis was to study the distribution (intratumoral) of the radiotracer and corroborate the smallanimal PET image findings at the selected time point $(2.5 \mathrm{~h})(5,6)$.

In our article, we did not intend to make any suggestions on the metabolism of EF5 or ${ }^{18} \mathrm{~F}-\mathrm{EF} 5$, including nonhypoxic metabolism in vivo (7). We think that the observed effect of lower intratumoral contrast in $\mathrm{H} 460$ tumors at $2.5 \mathrm{~h}$ after injection of ${ }^{18} \mathrm{~F}-\mathrm{EF} 5$ in our study could be due to the presence of excess drug or due to slower clearance of the radiotracer from nonhypoxic tumor regions (areas not positive for EF5 adducts) when the radiotracer was coadministered with unlabeled EF5 at a $30 \mathrm{mg} / \mathrm{kg}$ dose. We note that this is in line with the suggestion of Koch and Evans that the 10-fold difference in drug concentration between the group of animals receiving radiotracer alone and the group receiving radiotracer coinjected with EF5 (30 mg/kg) could have caused changes in drug half-life and possibly affect the pharmacokinetic loss of unbound drug $\left({ }^{18} \mathrm{~F}-\mathrm{EF} 5\right)$ in $\mathrm{H} 460$ tumors in rats. Given the longer half-life of EF5 in rats, imaging at later time points (e.g., $>3 \mathrm{~h}$ ) may allow better clearance of the unbound radiotracer and further improve the contrast between hypoxic and nonhypoxic tumor regions in tumors grown in rats and at the $30 \mathrm{mg} / \mathrm{kg}$ dose $(100 \mu \mathrm{M})$.

With regard to the statement "the authors suggest that uptake of 2-nitroimidazoles such as EF5 selects for tissues that have a partial pressure of oxygen less than $10 \mathrm{~mm} \mathrm{Hg}$," again, we would like to clarify that we used "partial pressure of oxygen $<10 \mathrm{~mm} \mathrm{Hg}$ " only in the introduction section (as a parenthesis to a sentence) to provide general information that tumor retention of 2-nitroimidazole-based hypoxia tracers typically reflects partial pressure of oxygen values less than $10 \mathrm{~mm} \mathrm{Hg}$, as the binding rate of 2-nitroimidazole hypoxia markers increases sharply at partial pressure of oxygen values less than $10 \mathrm{~mm} \mathrm{Hg}(8-10)$. The full sentence reads as follows: "With the exception of ${ }^{64} \mathrm{Cu}$-diacetyl-bis $\left(N^{4}\right.$-methylthiosemicarbazone), current small-molecule PET hypoxia tracers consist of a 2-nitroimidazole moiety that forms the basis for their selective uptake in hypoxic tumor cells (partial pressure of oxygen $<10 \mathrm{~mm} \mathrm{Hg}$ )." In our studies of the 3 tumor models, PC3 tumors displayed a distinctive pattern of hypoxia as indicated by large regions of EF5 binding in immunohistochemical images. In some tumors, the intensity of EF5 binding increased from the center to the outer margin of hypoxic regions. This binding pattern of EF5 in PC3 tumors appears consistent with the macroscopic regions of hypoxia reported by the Koch group in rat 9L gliosarcoma tumors (11).

\section{REFERENCES}

1. Chitneni SK, Bida GT, Zalutsky MR, Dewhirst MW. Comparison of the hypoxia PET tracer ${ }^{18}$ F-EF5 to immunohistochemical marker EF5 in 3 different human tumor xenograft models. J Nucl Med. 2014;55:1192-1197.

2. Ziemer LS, Evans SM, Kachur AV, et al. Noninvasive imaging of tumor hypoxia in rats using the 2-nitroimidazole ${ }^{18}$ F-EF5. Eur J Nucl Med Mol Imaging. 2003; 30:259-266.

3. Koch CJ, Shuman AL, Jenkins WT, et al. The radiation response of cells from 9L gliosarcoma tumours is correlated with F18-EF5 uptake. Int J Radiat Biol. 2009;85:1137-1147.

4. Komar G, Seppaenen M, Eskola O, et al. ${ }^{18}$ F-EF5: a new PET tracer for imaging hypoxia in head and neck cancer. J Nucl Med. 2008;49:1944-1951.

5. Busk M, Horsman MR, Jakobsen S, et al. Imaging hypoxia in xenografted and murine tumors with ${ }^{18} \mathrm{~F}$-fluoroazomycin arabinoside: a comparative study involving microPET, autoradiography, PO2-polarography, and fluorescence microscopy. Int J Radiat Oncol Biol Phys. 2008;70:1202-1212.

6. Carlin S, Zhang H, Reese M, Ramos NN, Chen Q, Ricketts SA. A comparison of the imaging characteristics and microregional distribution of 4 hypoxia PET tracers. J Nucl Med. 2014;55:515-521.

7. Eskola O, Gronroos TJ, Forsback S, et al. Tracer level electrophilic synthesis and pharmacokinetics of the hypoxia tracer $\left[{ }^{18}\right.$ F]EF5. Mol Imaging Biol. 2012;14: 205-212.

8. Krohn KA, Link JM, Mason RP. Molecular imaging of hypoxia. J Nucl Med. 2008;49(suppl 2):129S-148S.

9. Raleigh JA, Chou SC, Arteel GE, Horsman MR. Comparisons among pimonidazole binding, oxygen electrode measurements, and radiation response in $\mathrm{C} 3 \mathrm{H}$ mouse tumors. Radiat Res. 1999;151:580-589.

10. Barthel $\mathrm{H}$, Wilson $\mathrm{H}$, Collingridge $\mathrm{DR}$, et al. In vivo evaluation of $\left[{ }^{18} \mathrm{~F}\right]-$ fluoroetanidazole as a new marker for imaging tumour hypoxia with positron emission tomography. Br J Cancer. 2004;90:2232-2242.

11. Koch CJ, Jenkins WT, Jenkins KW, et al. Mechanisms of blood flow and hypoxia production in rat $9 \mathrm{~L}$-epigastric tumors. Tumor Microenviron Ther. 2013;1:1-13.

Satish K. Chitneni* Gerald T. Bida

Michael R. Zalutsky

Mark W. Dewhirst

*Duke University Medical Center Box 3808

Durham, NC 27710

E-mail: satish.chitneni@duke.edu

Published online Mar. 5, 2015 DOI: 10.2967/jnumed.115.154054 